\title{
Phonetics of Polish "soft"-"hard" vowel allophony
}

Steven M. Lulich, and Malgorzata E. Cavar

Citation: The Journal of the Acoustical Society of America 146, 2263 (2019); doi: 10.1121/1.5127834

View online: https://doi.org/10.1121/1.5127834

View Table of Contents: https://asa.scitation.org/toc/jas/146/4

Published by the Acoustical Society of America

\section{ARTICLES YOU MAY BE INTERESTED IN}

Rippled-spectrum resolution dependence on frequency: Estimates obtained by discrimination from rippled and nonrippled reference signals

The Journal of the Acoustical Society of America 146, 2231 (2019); https://doi.org/10.1121/1.5127835

Broadband sound propagation in a seagrass meadow throughout a diurnal cycle

The Journal of the Acoustical Society of America 146, EL335 (2019); https://doi.org/10.1121/1.5127737

Phonetic change in an Antarctic winter

The Journal of the Acoustical Society of America 146, 3327 (2019); https://doi.org/10.1121/1.5130709

Articulatory and acoustic characteristics of the Korean and English word-final laterals produced by Korean female learners of American English

The Journal of the Acoustical Society of America 146, EL444 (2019); https://doi.org/10.1121/1.5134656

Void fraction, number density of acoustic cavitation bubbles, and acoustic frequency: A numerical investigation

The Journal of the Acoustical Society of America 146, 2240 (2019); https://doi.org/10.1121/1.5126865

A model of speech production based on the acoustic relativity of the vocal tract

The Journal of the Acoustical Society of America 146, 2522 (2019); https://doi.org/10.1121/1.5127756

Advance your science and career as a member of the 


\title{
Phonetics of Polish "soft"-"hard" vowel allophony"
}

\author{
Steven M. Lulich ${ }^{1, b)}$ and Malgorzata E. Cavar ${ }^{2}$ \\ ${ }^{1}$ Department of Speech and Hearing Sciences, Indiana University, Bloomington, Indiana 47405, USA \\ ${ }^{2}$ Department of Linguistics, Indiana University, Bloomington, Indiana 47405, USA
}

(Received 6 December 2018; revised 30 July 2019; accepted 13 September 2019; published online 9 October 2019)

This paper reports on the results of a three-dimensional ultrasound study of Polish vowels in consonant-vowel sequences. It was found that allophonic variation in vowels in the context of "soft" consonants is consistently implemented phonetically by means of tongue root advancement, which effectively expands the pharyngeal cavity and reduces the volume of the oral cavity. The tongue root is also consistently advanced in the soft consonants that trigger vowel allophony and retracted (or neutral) in the "hard" sounds, which do not trigger allophony, suggesting that tongue root advancement is part of the phonological representation of the "softness" (or palatalization) contrast. In parallel to this allophony, the same tongue root mechanism was found to underlie the phonotactic distribution of the phonemic vowels $/ \mathrm{i} /$ and $/ \mathrm{i} /$, yielding an entirely symmetric system with consonant-vowel sequences always obligatorily compatible in terms of the position of the tongue root. (C) 2019 Acoustical Society of America. https://doi.org/10.1121/1.5127834

Pages: 2263-2278

\section{INTRODUCTION}

The feature advanced tongue root (or [ATR]) was first introduced by Stewart (1967) in his account of vowel harmony in Akan, although references to tongue root position as an important factor in phonological processes goes back at least to Pike (1947). Advancement of the tongue root is related to widening of the pharyngeal cavity, which led Lindau to propose the feature (expanded) as a replacement for [ATR] (Lindau, 1975, 1978). A strong relationship between advancement of the tongue root and raising of the tongue body has also been observed (Halle and Stevens, 1969; Ladefoged et al., 1972). As Archangeli and Pulleyblank (1994) observe, "movement of the tongue root tends to be accompanied by a sympathetic movement of the tongue body" (cf. also Washington, 2016). It is widely agreed that [+ATR] vowels have lower first formant frequency $(\mathrm{F} 1)$ than their [-ATR] counterparts (Halle and Stevens, 1969), but opinions and evidence regarding the effect of tongue root advancement on F2 is more varied (Beltzung et al., 2018; Lindau, 1978). In addition, lowering of F3 has been observed in some languages (e.g., Catford, 1988, for Caucasian languages, and Aralova et al., 2008, for Even, a Tungusic language). Hess (1988) and Ladefoged and Maddison (1996) posit narrower bandwidths for all formants in [+ATR] vowels.

The feature [ATR] has primarily been used in the analysis of vowel harmony systems (cf. Beltzung et al., 2018, for a comprehensive overview of the literature). Since the 1960 s it has become clear that many languages around the world are characterized in part by [ATR] vowel harmony, including Akan (Tiede, 1996), Dagbani (Hudu, 2010), Maa (Guion et al., 2004), Western and Tsongol Buriat (Kang and Ko,

\footnotetext{
${ }^{\text {a) }}$ Portions of this work were presented in Proceedings of Meetings on Acoustics, meeting of the Acoustical Society of America, Boston, MA, 25-29 June 2017, and in a poster presented at the Acoustical Society of America, Minneapolis, MN, 7-11 May 2018.

b)Electronic mail: slulich@indiana.edu
}

2012), and Oroqen (Lulich and Whaley, 2012). In a typical [ATR] harmony language, every suffix vowel must be [+ATR] if the last vowel in the stem is [+ATR], and every suffix vowel must be [-ATR] if the last vowel of the stem is [-ATR]. In some instances there may be co-occurrence constraints on the consonants in these stems and suffixes. For example, uvular stops (e.g., /q/) may be restricted to [-ATR] contexts while velar stops (e.g., $/ \mathrm{k} /$ ) are restricted to [+ATR] contexts (Ard, 1983). There is also evidence that [+ATR] vowels can cause neighboring consonants to become palatalized. An example of this is the language Tohono O'odham (Hill and Zepeda, 1992), in which the high vowels /i/, /e/, and /u/ all palatalize preceding coronal consonants, while the non-high vowels /o/ and /a/ do not palatalize their neighbors and are characterized by tongue root retraction. Discussion of the effects of [ATR] on consonants has largely been restricted to laryngeal contrasts (e.g., in Buchan Scots, Trigo, 1986; in Armenian dialects, Vaux, 1992; in American English, Keyser and Stevens, 2006). Recently, [ATR] has been invoked in analyses of emphatic consonants and gutturals in Arabic (Rose, 1996), secondary pharyngealization in Chilcotin (a Northern Athabascan language, cf. Hansson, 2001), and retroflexion in Chumburung (Pulleyblank, 2015). Bennett et al. (2018) observed a role for the tongue root in Irish palatalization independent of tongue body position, and Cavar (2004, 2007,2018 ) posited on phonological grounds that the feature [ATR] is involved in consonant palatalization in Polish (also called "softening"), although palatalization phenomena are typically described in terms of features associated with the tongue blade or dorsum. Her proposals are based on the phonological "soft"-"hard" allophony of vowels in Polish, and an examination of the phonetic evidence for those proposals are the focus of this paper.

The Polish sound inventory includes six vowel phonemes $(/ \mathrm{i}, \dot{\mathrm{i}}, \mathrm{e}, \mathrm{a}, \mathrm{o}, \mathrm{u} / \mathrm{)})$, a number of "neutral" consonants (e.g., /p, t, k/), and a set of soft and hard posterior sibilants 
(/t $\zeta, \mathrm{tz}, \mathrm{tš}, \mathrm{tž}, \boldsymbol{\zeta}, \mathrm{z}, \mathrm{s}, \mathrm{z} /$. Historically, the hard sibilants (/ťs, tž, $s, z_{6} /$ ) originated from a well-known process of "second velar palatalization," which parallels the process of "velar softening" in English. The soft sibilants (/t $6, \mathrm{t} z,, 6, \mathrm{z} /)$ subsequently developed from a process called "coronal palatalization" that affected coronal consonants, which is parallel to the equivalent process in English. An important difference between the phonologies of English and Polish is the relatively small number of vowel phonemes in Polish and a corresponding larger number of phonological processes that cause alternations between allophones of the vowels. One such allophony is triggered by the soft vs hard consonants.

According to earlier literature, there is a systematic effect of tongue body fronting and/or raising in Polish vowels in the context of soft consonants (e.g., Sawicka, 1995; Wisniewski, 1997). In particular, it has been claimed that $/ \mathrm{u} /$ becomes fronted, /a/ becomes raised, and mid vowels become both fronted and raised in this context. The vowels /i/ and /i/ do not participate in this allophony, but are subject to related phonotactic constraints. Specifically, /i/ cannot co-occur with soft consonants, while /i/ cannot co-occur with hard consonants. In addition, /i/ causes "secondary palatalization" of the preceding neutral consonants, unlike all other vowels in Polish.

Cavar (2004, 2007, 2018) suggested that the allophonic and phonotactic distribution of Polish front vowels is governed by the distinctive feature [ATR] with fronting and raising of the tongue body viewed as collateral effects (no claims were made about Polish back vowels). Although x ray data for Polish exist from the 1950s and 1960s (Koneczna and Zawadowski, 1951; Wierzchowska, 1967), we are not aware of any articulatory studies addressing the contextual variants of vowels adjacent to soft or hard consonants.

In this paper we report the results of an ultrasound study of the articulation of vowels in Polish. The first aim of the present study is to provide an articulatory phonetic description of Polish vowel allophony. A second aim is to determine whether a phonological interpretation of the allophony in terms of [ATR] is supported phonetically. The allophony is triggered in the context of soft consonants, and thus whichever phonetic quality differentiates the two sets of allophones, it is not an integral feature of the vowel itself. To pinpoint the feature underlying the allophonic contrast, it is therefore necessary to examine the triggers of the allophony - the soft consonants themselves - and how these differ from other consonantal series in Polish. To this end, we focus on the contrast between soft and hard sibilants and provide an articulatory phonetic description of this contrast. This description, in turn, allows us to test whether the feature responsible for the allophony could be [ATR]. The third aim of the present study is to determine whether articulatory phonetic evidence supports viewing the contrast between /i/ and /i/ as identical to the allophonic contrast among the other Polish vowels. To the extent that Polish soft-hard distinctions and consonant palatalization are ultimately found to involve [ATR], it is likely that [ATR] underlies equivalent distinctions and palatalization in other languages (especially other Slavic languages).
The articulatory phonetic details of the realization of the Polish vowels in soft and hard environments, and the phonological interpretation of the findings, are the focus of this study. In particular, it is argued in this paper that (1) assimilation in terms of tongue root position is the driving force for Polish vowel allophony, (2) tongue root position is the core distinction between the vowels /i/ and / $\mathbf{i} /$, and (3) tongue root position is also the core distinction between the soft and hard sibilants. Finally, in light of these findings, we propose that these phonetic distinctions reflect phonological distinctions in terms of the feature [ATR].

\section{METHODS}

\section{A. Participants}

Data collection and analysis were carried out in two phases. For the first phase of the study, five native speakers of Polish (3 females, 2 males) participated. Three speakers (speakers 1, 4, and 5) were from Warsaw in central Poland, one (speaker 2) was from Lublin in eastern Poland, and one (speaker 3) was from southern Poland. Speakers 2 and 3 later lived in Torun in north-central Poland. The participants were between 35 and 44 years of age and speakers of standard Polish (Dejna, 1983, 1994; Greenberg et al., 2017). All five speakers were either employed or enrolled as graduate students at Indiana University. Three of the speakers (speakers 1-3) had lived outside of Poland for over ten years, although their Polish speech had no detectable foreign accent, as informally assessed by author M.C. (speaker 1). Differences between the speakers with a history of prolonged residence outside of Poland and those without such a history were perceptually negligible, and so all of the data were included in a single set of analyses. Although speaker 1 was not naive to the purpose of the study, the other four speakers were. There were no perceptible dialectal differences among the five speakers.

For the second phase of the study, an additional five native speakers of Polish (2 females, 3 males) participated and were demographically similar to the five speakers from the first phase of the study. Three of the speakers (speakers 6, 7, and 9) were from Warsaw in central Poland, one (speaker 8) was from Lodz in central Poland, and one (speaker 10) was from Lublin in Eastern Poland. These participants were between 42 and 58 years of age, and were speakers of standard Polish. All five were either employed or enrolled as graduate students at Indiana University, and four (speakers 6, 7, 9, and 10) had lived outside of Poland for over ten years, although their Polish speech had no detectable foreign accent.

The total number of participants in this study was ten $(5$ females, 5 males). ${ }^{1}$ Measures from the second phase of data collection were a subset of those from the first phase of data collection. The second phase was carried out to test the generalizability of findings based on the first phase, and therefore data from the two phases were analyzed separately. This procedure ensures that the findings have greater external validity (generalizability) than if the data had been analyzed together. 


\section{B. Speech materials}

\section{Phase 1}

This study focuses on stressed vowels in the initial syllable of disyllabic nonsense words of the form $C_{i} V_{j} C_{i} V_{j} C_{i}$, where all consonants in any word were identical and both vowels of the words were identical. Participants were instructed to read a word list presented in Polish orthography, which is phonetically unambiguous. The list included the nonsense word stimuli cicić, tytyt, ciecieć, tetet, ciaciać (speakers 1,2, and 5; or siasiaś, speakers 2 and 3), tatat, ciocioć, totot, ciuciuć, and tutut, together with 13 additional filler nonsense words of the same form. The list was read three times in the same order. These stimuli included all oral vowels in the context of bilateral obstruent consonants representing neutral and soft places of articulation. This list was used for the analysis of Polish vowels, as presented below in Secs. IV A and IV C. Due to investigator error, speakers 3 and 4 did not record the vowel phoneme $/ \mathrm{u} /$ in either soft or neutral contexts.

A second list was read by each participant in order to investigate the consonants that trigger the vowel allophony, namely the soft consonants $c i(/ \mathrm{t} \varphi /)$, si $(/ / /)$, and the hard consonants $c z(/ \mathrm{ts} /)$, and $s z(/ \mathrm{s} /)$. This list included the real word stimuli (in Polish orthography) ciska ("s/he throws"), Czyngiz (the personal name "Genghis"), pasza (a highranking official of the Ottoman Empire, "pasha"), and Kasia (the diminutive form of the name "Katherine"), together with additional real word fillers. This list was read three times in the same order. The description of consonants in Sec. IV B is based on the recordings from this second list.

Polish words are generally characterized by penultimate stress placement, which helped ensure that the initial syllable of each word would be uniformly stressed by all speakers throughout the experiment. Both authors listened to each of the recorded words independently, and found no instance of stress placed on the final syllable.

\section{Phase 2}

The speakers in the second phase of the study read a word list presented in Polish orthography with nonsense word stimuli cicić, tytyt, ciecieć, tetet, ciaciać, tatat, ciocioć, totot, ciuciuć, and tutut, together with additional filler nonsense words of the same form. The list was read two times in the same order. As in the first phase of the study, this list was used for the analysis of Polish vowels.

Additional nonsense words were read by each participant in order to investigate the consonants that trigger the vowel allophony, namely the soft consonant $c i(/ \mathrm{t} / /)$ and the hard consonant $c z(/ \mathrm{tš} /)$. These nonsense word stimuli were of the same form as the vowel stimuli, namely cicić, ciaciać, $c z y c z y c z$, and czaczacz.

\section{Instrumental data collection}

For our study, ultrasound images were recorded with a Philips EPIQ $7 \mathrm{G}$ system (Bothell, WA) using an xMatrix x6-1 digital 3D/4D (three-dimensional/four-dimensional) transducer (Philips, Bothell, WA; Lulich et al., 2018) secured under the chin using an Articulate Instruments ultrasound stabilization headset (Edinburgh, UK; Scobbie et al., 2008). In this way the transducer is always in a stable position relative to the external points of reference, such as the palate, which allows us to evaluate the relative movement of the tongue during articulation in reference to the passive articulator (Charles and Lulich, 2018, 2019). Fully uncompressed digital imaging and communications in medicine (DICOM) ultrasound files were transferred to a Windows 7 (Microsoft Corp., Redmond, WA) computer for analysis. Ultrasound files were analyzed using a custom MATLAB toolbox (The MathWorks, Natick, MA), called "WASL," developed in the Speech Production Laboratory at Indiana University. ${ }^{2}$ Together with the ultrasound data, audio was synchronously recorded with a SHURE KSM32 microphone (Niles, IL) placed approximately $1 \mathrm{~m}$ in front of the participant with a sampling rate of $48 \mathrm{kHz}$.

The ultrasound images generated by the system used in this study were "native data" images (manufacturer's terminology for their proprietary data format), which were presumably (although not certainly) scan converted data without further image processing in either the spatial or temporal domains (see Lulich et al., 2018, for further technical details). The only image processing that we carried out during data analysis was the threshold and overlay $(\mathrm{TaO})$ process described in Sec. III B.

Synchronization of audio and ultrasound recordings was accomplished using the method described by Lulich et al. (2018). Specifically, a foot pedal was used to trigger both the ultrasound system and a separate computer recording audio. Both the beginning and end of the recording were triggered by the same foot pedal. Empirical tests showed that the beginning of ultrasound recording included a lag time of variable duration, whereas the end of ultrasound recording was more consistent and immediate. Synchronizing the audio and the ultrasound data from the end of the recording is associated with a maximum uncertainty of approximately $30 \mathrm{~ms}$ for the ultrasound system used in this study. The uncertainty can be reduced to as little as the ultrasound frame duration, based on events within both the audio and ultrasound recordings such as stop releases and turning points (i.e., velocity minima) in articulatory movements and formant trajectories. For low frame rates the uncertainty remains approximately $30 \mathrm{~ms}$ even if the frame duration is greater than this.

Ultrasound frame rates for 3D/4D imaging are slower than those typically achieved during two-dimensional (2D) ultrasound imaging, because of the trade-off between the size of the volume to be imaged and the speed of acquiring the image (see Lulich et al., 2018). For the first phase of this study the frame rates were between 9.3 and 15.0 frames per second (fps), while for the second (replication) phase of the study the frame rates were between 19.2 and 21.5 fps. Spatial resolution (i.e., the dimensions of a voxel) was approximately $0.9 \mathrm{~mm}$ in the anterior-posterior and medial-lateral directions, and approximately $0.4 \mathrm{~mm}$ in the inferior-superior direction.

\section{Acoustic data analysis}

Audio recordings were analyzed with Praat (Boersma and Weenink, 2018). Formant frequencies were extracted 
from the midpoint of each vowel following the hard or soft consonant, using the Burg algorithm with default Praat parameters for window length $(0.025 \mathrm{~s})$, number of formants (4), and maximum formant frequency $(3000 \mathrm{~Hz})$. Formant frequencies were manually checked and, in $\approx 2 \%$ of tokens, corrected.

\section{E. Statistical analysis}

Separate Kolmogorov-Smirnov tests of normality were applied to each of the articulatory and acoustic data variables pooled across vowels and speakers, and grouped by speaker. Almost all of the pooled variables were non-normally distributed, so non-parametric Kruskal-Wallis tests were applied to check for main effects of speaker and vowel. Wilcoxon signed-rank tests were used to evaluate the significance of differences between "softness" and "hardness" in the vowels and consonants. One-tailed Wilcoxon signedrank tests were used when differences were expected in a specific direction, and two-tailed tests were used (for F2 and F3) when the direction of differences was not predicted $a$ priori. For variables grouped by speaker, all of the articulatory variables were normally distributed, and $t$-tests were applied; almost all of the acoustic variables were nonnormally distributed, and Mann-Whitney $U$ tests were applied. Because each test was applied a total of 15 times, we used a conservative $\alpha=0.05 / 15=0.0033$ for determining statistical significance.

\section{FRAMEWORK FOR ARTICULATORY ANALYSIS}

\section{A. Anatomical definitions}

Delineations between the various parts of the tongue are not universally agreed upon, and hence it is necessary to define our criteria for identifying different parts of the tongue, especially the tongue root. For this paper, we adopt an anatomically oriented definition. Since the tendon of the genioglossus (GGp), the muscle of the geniohyoid (GH), and the hyoid bone are all readily identifiable within ultrasound images, as Fig. 1(A) demonstrates (Stone, 2005), we use these anatomical landmarks to define and identify the different parts of the tongue, as illustrated in Fig. 1(B).

We define the tongue root as being that part of the tongue surface which is directly opposite to the tendon of the GGp. Contraction of the GH or the posterior part of the GGp has the effect of pulling the tongue root forward (Halle and Stevens, 1969; Honda, 2008; Saugusa et al., 2001; Trigo, 1991) and creating a groove in the posterior half of the tongue midline (Niimi and Simada, 1980; Stone and Lundberg, 1996). Contraction of the GH also elevates/advances the hyoid bone (Hiiemae et al., 2002), which we hypothesize might also pull the tongue root forward. We define the tongue dorsum as being that part of the tongue surface that can be directly acted upon by the medial portion of the genioglossus muscle (GGm). The tongue blade is defined as the part of the tongue surface that can be directly acted upon by the anterior portion of the GGp muscle (GGa). Finally, the tongue tip is defined as the portion of the tongue surface anterior to the tongue blade.

Multiple muscles besides GGa, GGm, GGp, and GH cooperate to shape and position the tongue, but we chose to define the parts of the tongue in terms of GGa, GGm, GGp, and $\mathrm{GH}$ because these muscles are visible in tongue ultrasound and functionally closely related to the articulatory gestures hypothesized to be involved in Polish vowel allophony. It must be noted that these anatomical definitions can only be imperfectly realized in the interpretation of ultrasound images because the delineations between GGa, GGm, and GGp cannot be unequivocally identified.

Finally, we do not assume that a distinctive feature (such as [ATR]) is implemented by a perfectly consistent contraction of a specific muscle in every instance to the exclusion of other muscles. Rather, we recognize that the articulation of speech sounds is a complex activity that recruits different combinations of muscles with varying degrees of contraction in different instances, based on phonological context, the direction of the pull of gravity, social context, and other aspects of the speech act's "environment." On the other hand, we do assume the converse, namely, that evidence of consistent contraction of specific muscles is
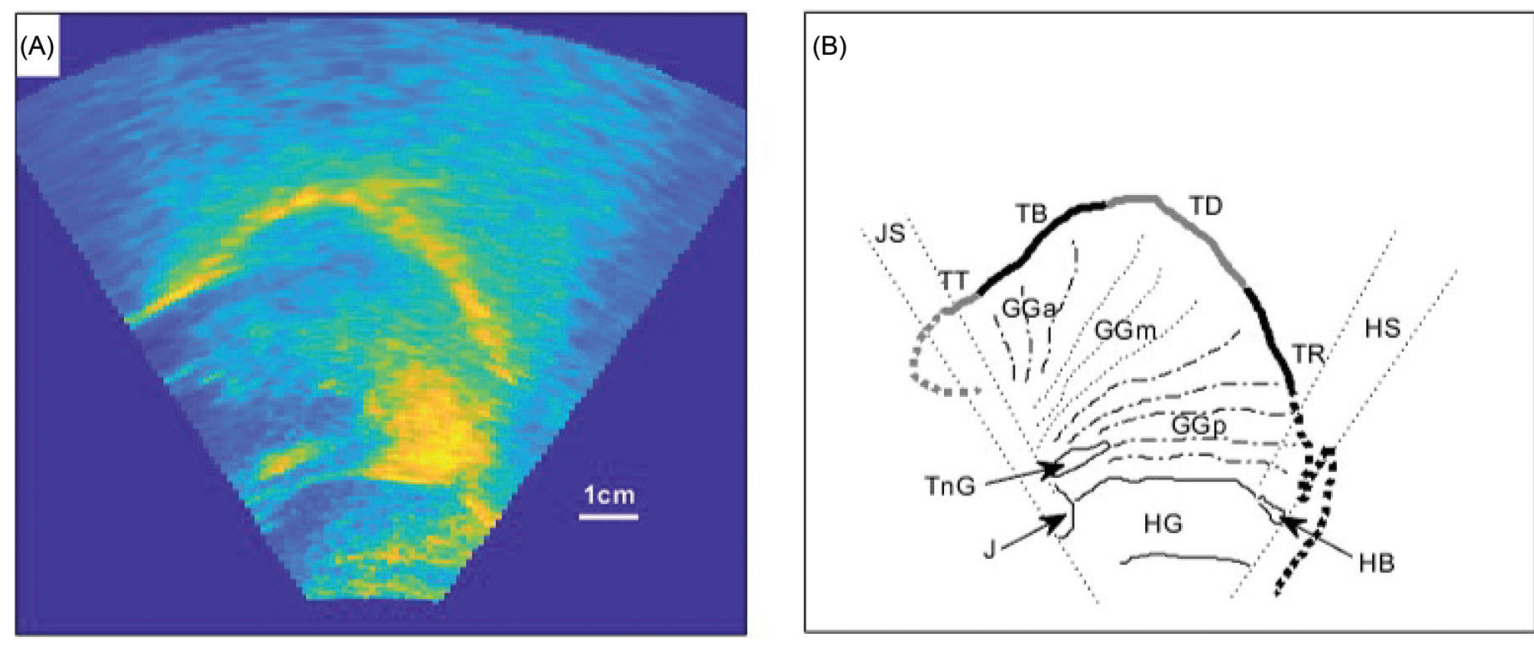

FIG. 1. Ultrasound image of the tongue of speaker 5 (A), and a schematic representation of the same image (B). Anatomical features and landmarks in (B) are drawn directly from the ultrasound image in (A). The tongue tip is to the left in both panels. Green, hyperechoic regions; blue, hypoechoic regions. 
likely due to the implementation of specific distinctive features. In particular, we posit that consistent evidence of GGp or GH contraction indicates the implementation of the feature [ATR], and we therefore center the present study around the evaluation of such evidence.

The anatomical considerations briefly discussed in the preceding paragraphs motivate our measures and interpretation of the study results, but it is important to note that the findings are not dependent on assumptions about the anatomical implementation of phonological features. Ultrasound recordings were analyzed for each soft-context vs neutralcontext vowel pair to determine whether or not tongue root advancement consistently differentiated between them. In making such a determination, we relied on the following procedures.

\section{B. $\mathrm{TaO}$}

Ultrasound images are 2D arrays of pixels with specified color (or grayscale) values based on echo intensities. Although it has not commonly been performed in phonetic ultrasound research for the purpose of data visualization, it is possible to assign a threshold pixel value and generate a new image in which the only pixels displayed are those with intensity greater than the threshold value. Given an appropriate threshold, two such images can be overlaid on the same axis without significantly interfering with the visualization of either one. Assigning different color schemes to each image further enhances visualization of both images. The benefit of $\mathrm{TaO}$ is that it allows for a direct visual comparison between images displayed on the same axis. Figure 2 shows an example in which a pair of grayscale ultrasound images is first thresholded, then assigned different color schemes, and finally overlaid. The images are of the vowel phoneme /e/ in its two allophonic contexts, i.e., between two soft affricates (in the Polish nonce word ciecieć) and between two neutral alveolar stops (in the Polish nonce word tetet). The tongue tip is to the left. It should be noted that the tongue surface itself appears in ultrasound images as the lower edge of the bright, suprathreshold pixels that remain visible in $\mathrm{TaO}$ images. The suprathreshold pixels above this lower edge are artifacts caused by reverberation of the ultrasound waves at the tissue-air interface, affected by the roughness of the tongue surface and presence of saliva. While $\mathrm{TaO}$ images show only the suprathreshold pixels, the tissue-air interface remains visible as the lower edge of these pixels, and differences between the two tongue shapes shown are accurately portrayed.

\section{Tongue anatomy features}

Tongue surface and internal features were examined based on the raw ultrasound and $\mathrm{TaO}$ images. This study is centered around an evaluation of the evidence for tongue root advancement (e.g., as might be caused by GGp or GH contraction) during vowels in soft contexts (when the vowels are hypothesized to be $[+\mathrm{ATR}])$ and the lack of such evidence during vowels in neutral contexts (when the vowels are hypothesized to be $[-\mathrm{ATR}])$. All measurements were based on identifying the tongue surface as the lower edge of the suprathreshold pixels. Types of evidence for tongue root advancement are illustrated in Fig. 3 and include:

(1) Advancement of the tongue root, visible in the midsagittal plane. Since GGp contraction pulls the tongue root forward toward the tendon of the GGp, tongue root advancement was quantified as the Euclidean distance between the tongue root in the soft vs neutral vowel allophones, measured along a line parallel to the tendon of the GGp and within the midsagittal plane, which is presumably the primary line of force generation during GGp contraction. If the line pointed to a part of the tongue root that was obscured by the hyoid shadow, the nearest visible part of the tongue root was measured.

(2) Presence of a deep midline groove in the tongue root, visible in the coronal plane. Since GGp is a bilateral muscle running on either side of the midsagittal plane, contraction of GGp pulls the medial part of the tongue root forward, without pulling forward the lateral sides of the tongue root. This creates a midline groove. The depth of the midline groove was quantified as the vertical distance between the bottoms of the grooves in the soft vs



FIG. 2. Example of TaO from speaker 5. Two raw ultrasound images are thresholded, given new color schemes, and then overlaid on the same graph. The tongue tip is to the left in all panels. Green, prepalatal context; blue, neutral context. 

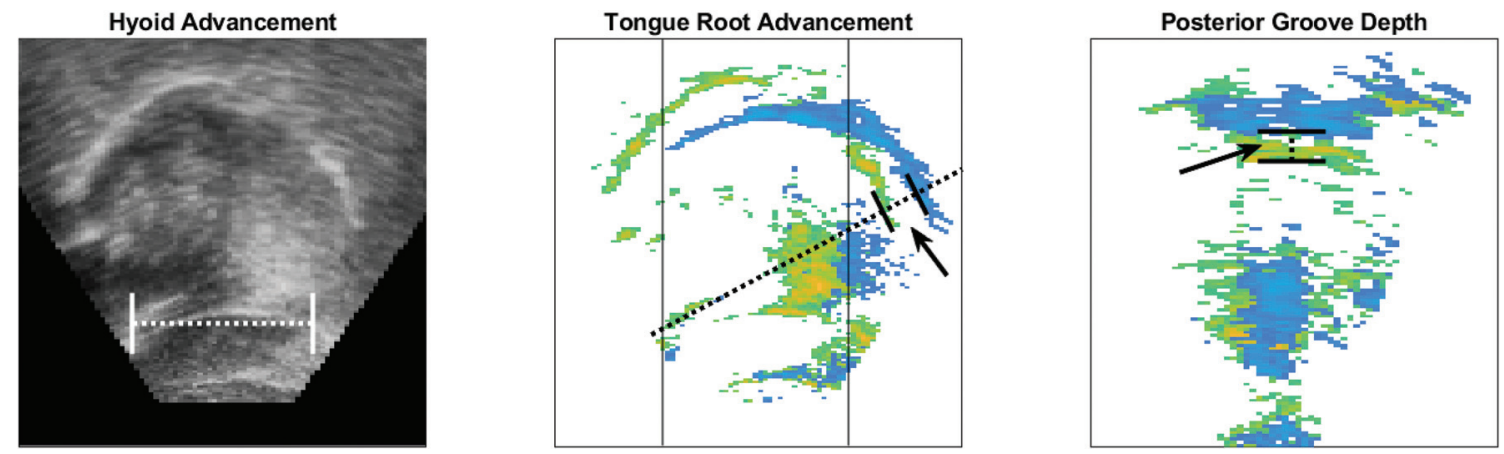

FIG. 3. Evidence of [+ATR] from speaker 5. A raw ultrasound image (left) shows how the distance from the tendon of the GGp to the hyoid shadow was measured. TaO images (middle,right) show how tongue root advancement and groove depth were measured. Green, prepalatal context; blue, neutral context.

neutral vowel allophones. These measurements were made within a coronal plane that was as posterior as possible while the bottoms of the grooves were still visible in all of the examined vowels and consonants (for example, see Fig. 5). The location of the coronal plane was speaker specific but constant within each speaker.

(3) Elevation and/or advancement of the hyoid bone, visible in the midsagittal plane. Since $\mathrm{GH}$ is attached to the front of the mandible and hyoid bone, contraction of GH pulls the hyoid bone toward the front of the mandible. Hyoid elevation/advancement was quantified by first measuring the Euclidean distance between the tendon of the GGp and the anterior end of the acoustic shadow cast by the hyoid in both the soft vs neutral vowel allophones within the midsagittal plane, and then subtracting the measured distance in the neutral allophone from the measured distance in the soft allophone. If the hyoid shadow was not visible in one of the vowel allophones, hyoid elevation was coded as "visible" or "not visible."

Contrary evidence (indicative of tongue root retraction, or at least the lack of tongue root advancement) could include retraction of the tongue root (visible in the midsagittal plane), lack of a midline groove in the tongue root (visible in coronal plane), and lack of hyoid elevation (visible in the midsagittal plane). All measurements were made three times each.

In addition to specific evidence of tongue root involvement in Polish vowel allophony, we also noted evidence of tongue dorsum raising and fronting, as well as behavior of the tongue tip/blade. For the second phase of the study, a subset of measurements was made, focusing on advancement of the tongue root and the presence of a deep midline groove in the tongue root. It should be noted that, for the sake of brevity, we occasionally refer to the vowels in soft consonant contexts as "[+ATR] vowels" by hypothesis, and, similarly, we refer to the vowels in hard or neutral consonant contexts as " $[-\mathrm{ATR}]$ vowels." The assignment of phonological features is not assumed a priori, nor does it affect our phonetic analyses.

\section{RESULTS-PHASE 1}

\section{A. Articulatory phonetics of vowel allophony in soft vs neutral consonant contexts}

A summary of the statistical findings is presented in Table I for variables pooled across vowels and speakers. (Note that the phase 2 data are also given in Table I.) Figure 4 presents the results of the articulatory measures of vowel allophony in Polish. Across all speakers and all vowels (including /i/ and /i; see Sec. IV C), both the tongue root advancement and the groove depth in [+ATR] vowels were significantly greater than in [-ATR] vowels (see Table I). The same was true on an individual basis for speakers 1, 2, and 4. For speakers 3 and 5, the tongue root advancement was significantly greater in [+ATR] vowels [speaker $3, t=10.9719$, degrees of freedom $(\mathrm{DOF})=8$, $p<0.001$; speaker 5, $t=8.2462$, DOF $=14, p<0.001]$, but the groove depth was not different (speaker $3, p=0.9651$; speaker $5, p=0.0129$ ). Hyoid advancement could not be measured in speakers 2 and 3, and was not significantly different either across speakers $(p=0.9409)$ or individually (speaker $1, p=0.9550$; speaker 4, $p=0.013$; speaker $5, p=0.6076$ ).

With regard to tongue root advancement, four out of the five subjects (speakers 1, 2, 4, and 5) produced the [+ATR] vowels with the tongue root advanced by $0.52 \mathrm{~cm}$ on average. In speaker 3 the difference was small $(0.03 \mathrm{~cm}$, on average) but statistically significant. A similar pattern is observed for the posterior groove depth. In speakers 1, 2, 4, and 5, the posterior groove in the tongue root was $0.43 \mathrm{~cm}$ deeper, on average, across all of the [+ATR] vowels. In speaker 3 , the difference was small $(0.05 \mathrm{~cm}$, on average $)$ and not significant.

The distinction between speaker 3 and the rest of the speakers can be explained by the fact that speaker 3 had the poorest image quality overall, and the recorded images did not extend as far posterior as they did for the remaining four speakers. In other words, it is possible that the part of the tongue root responsible for advancing during the [+ATR] vowels simply was not visible.

In all five speakers, hyoid elevation/advancement was not consistently associated with the [+ATR] or [-ATR] vowels, contrary to expectation. In speakers 2 and 3, in particular, the hyoid shadow was never visible, and it was visible in speaker 4 only for the vowel /o/.

\section{B. Speaker 5}

Midsagittal and posterior coronal $\mathrm{TaO}$ images for the [+ATR] and [-ATR] allophones of the vowels /e/, /u/, /o/, and /a/ are shown in Fig. 5. For the vowel /e/, advancement of the tongue root in the $[+\mathrm{ATR}]$ allophone is apparent in the midsagittal $\mathrm{TaO}$ image, accompanied by raising and 
TABLE I. Summary statistics for each articulatory and acoustic variable, including the Kolmogorov-Smirnov (K-S) tests of normality, Kruskal-Wallis tests for main effects of speaker (K-W speaker) and vowel (K-W vowel), and Wilcoxon signed-rank (S-R) tests of significant differences. All Wilcoxon signedrank tests were one-tailed except for those tests evaluating differences in F2 and F3. Median values for the differences between soft and hard vowels and consonants are also provided as an indicator of effect size. Each test was applied 15 times, so a conservative $\alpha$ of $0.05 / 15=0.0033$ was used. Tests that were statistically significant are marked by an asterisk (*).

\begin{tabular}{|c|c|c|c|c|c|c|}
\hline Phase & Variable & $\mathrm{K}-\mathrm{S}$ & K-W speaker & K-W vowel & S-R & Median \\
\hline \multicolumn{7}{|l|}{ Vowels } \\
\hline 1 & $\mathrm{~F} 1$ & $p<0.001^{*}$ & $p=0.2816$ & $p<0.001 *$ & $p<0.001^{*}$ & $-59 \mathrm{~Hz}$ \\
\hline 1 & $\mathrm{~F} 2$ & $p<0.001^{*}$ & $p=0.0195$ & $p=0.0037$ & $p<0.001^{*}$ & $171 \mathrm{~Hz}$ \\
\hline 1 & $\mathrm{~F} 3$ & $p<0.001^{*}$ & $p=0.0569$ & $p<0.001^{*}$ & $p=0.1409$ & $-94 \mathrm{~Hz}$ \\
\hline 1 & Tongue root & $p<0.001 *$ & $p=0.0402$ & $p=0.4997$ & $p<0.001^{*}$ & $0.45 \mathrm{~cm}$ \\
\hline 1 & Groove & $p<0.001^{*}$ & $p=0.1303$ & $p=0.0118$ & $p<0.001^{*}$ & $0.36 \mathrm{~cm}$ \\
\hline 1 & Hyoid & $p=0.1547$ & $p=0.7575$ & $p=0.1596$ & $p=0.3711$ & $0.07 \mathrm{~cm}$ \\
\hline 2 & $\mathrm{~F} 1$ & $p<0.001^{*}$ & $p=0.2052$ & $p=0.0052$ & $p<0.001^{*}$ & $-36 \mathrm{~Hz}$ \\
\hline 2 & $\mathrm{~F} 2$ & $p<0.001^{*}$ & $p=0.8348$ & $p=0.0487$ & $p<0.001^{*}$ & $180 \mathrm{~Hz}$ \\
\hline 2 & $\mathrm{~F} 3$ & $p<0.001^{*}$ & $p=0.0208$ & $p=0.0032 *$ & $p=0.0249$ & $-144 \mathrm{~Hz}$ \\
\hline 2 & Tongue root & $p<0.001^{*}$ & $p=0.0889$ & $p=0.5314$ & $p<0.001^{*}$ & $0.36 \mathrm{~cm}$ \\
\hline 2 & Groove & $p<0.001^{*}$ & $p=0.0043$ & $p=0.6946$ & $p=0.0015^{*}$ & $0.21 \mathrm{~cm}$ \\
\hline \multicolumn{7}{|c|}{ Consonants } \\
\hline 1 & Tongue root & $p<0.001^{*}$ & $p=0.4961$ & $p=0.3472$ & $p<0.001^{*}$ & $0.79 \mathrm{~cm}$ \\
\hline 1 & Groove & $p<0.001^{*}$ & $p=0.6236$ & $p=0.9168$ & $p<0.001^{*}$ & $0.68 \mathrm{~cm}$ \\
\hline 2 & Tongue root & $p=0.0052$ & $p=0.9825$ & $p=0.0143$ & $p=0.0020 *$ & $0.61 \mathrm{~cm}$ \\
\hline 2 & Groove & $p=0.0054$ & $p=0.2487$ & $p=0.3272$ & $p=0.0039$ & $0.59 \mathrm{~cm}$ \\
\hline
\end{tabular}

moderate fronting of the tongue dorsum and blade. Importantly, the amount of tongue dorsum/blade raising appears to be equal to the amount of tongue root advancement, suggesting that the raising is a passive mechanical effect of volume preservation resulting from advancement of the tongue root. The increased groove depth in the [+ATR] allophone, which is apparent in the coronal $\mathrm{TaO}$ image, further supports this interpretation.

For the vowel $/ \mathrm{u} /$, the $[+\mathrm{ATR}]$ allophone displays tongue root advancement, this time accompanied by only
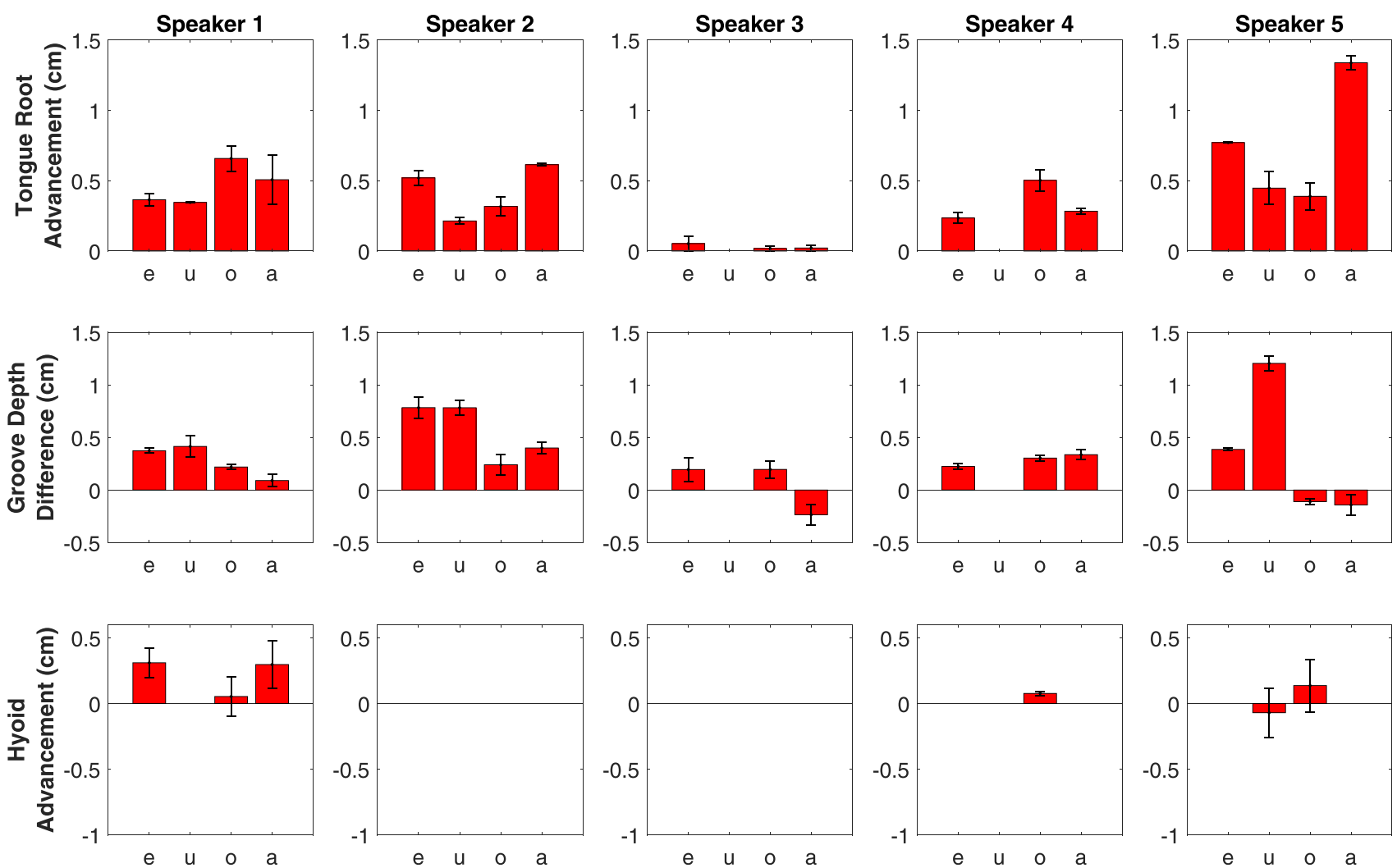

FIG. 4. (Color online) Measures of tongue root advancement, groove depth, and hyoid advancement for all five speakers in the soft vs neutral allophones of the vowels /e, u, o, a/. Bar heights show averages, and error bars show standard deviations over three measurements. 

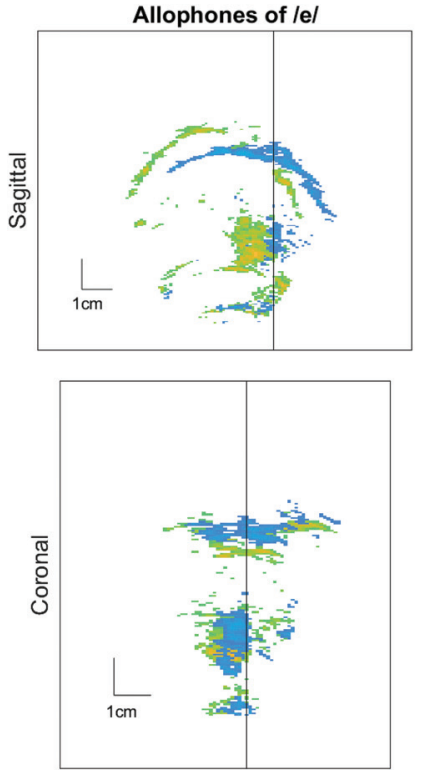
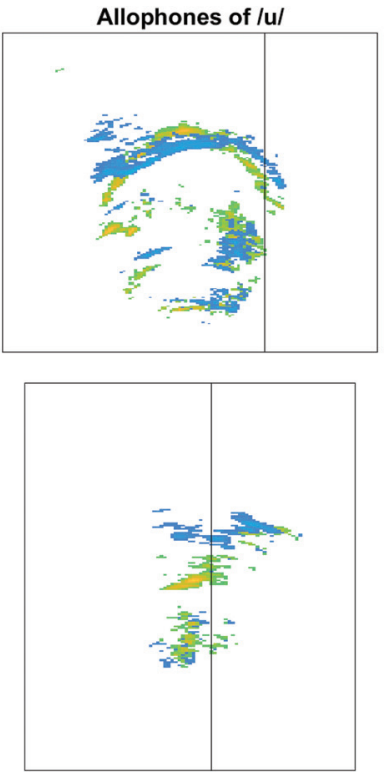
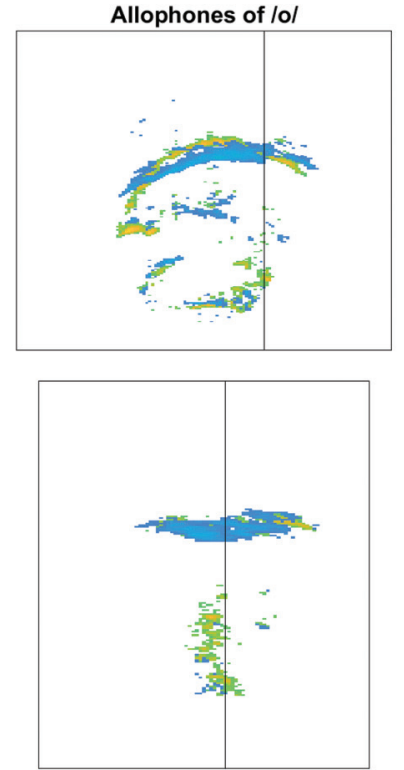
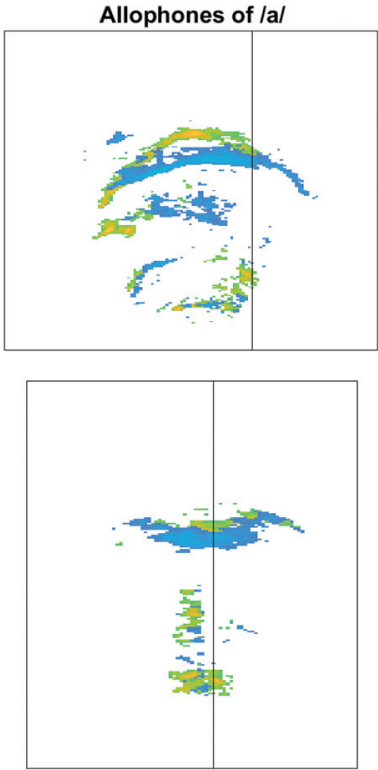

FIG. 5. Comparison of the words tetet vs ciecieć, tutut vs ciuciuć, totot vs ciocioć, and tatat vs ciaciać, produced by speaker 5 . The tongue tip is to the left in all panels of the top row. Green, prepalatal context; blue, neutral context.

slight raising, and fronting, and clear lowering of the tongue tip. In this instance, the tongue root groove appears to be very deep and asymmetrical.

For the vowel /o/, the [+ATR] allophone displays tongue root advancement over a shorter length of the visible tongue root, although the tongue root advancement may extend further into the parts of the tongue root that are not visible, either obscured by the hyoid shadow or outside of the field of view. There is no apparent difference in groove depth, but this could be because the coronal image is too far anterior to present such a difference. More posterior coronal images were very noisy and therefore not used. The tongue dorsum is minimally raised and fronted, while the tongue tip is lowered in the $[+\mathrm{ATR}]$ allophone, as with the vowel $/ \mathrm{u} /$.

For the vowel /a/, tongue root advancement in the [+ATR] allophone is apparent both from the orientation of the tongue root (it has a steeper negative slope than in the [-ATR] vowel and from the advanced position of the hyoid bone and its acoustic shadow, which obscures the most posterior part of the tongue root. As with the vowel /o/, a difference in the groove was not apparent, probably because the measurement was made too far anterior (the tongue root was not visible in more posterior coronal planes in the [+ATR] vowel). The tongue dorsum is raised and slightly fronted, and the tongue tip is lowered, as with the vowels $/ \mathrm{u} /$ and $/ \mathrm{o} /$.

Although speaker 5 presented some difficulties for measurements of tongue root advancement and posterior groove depth, these can be explained by factors such as obscurement by the hyoid shadow or posterior edge of the field of view. Raising of the tongue dorsum is slight or minimal in the [+ATR] allophones of two out of the four vowels, and dorsum fronting in the [+ATR] allophones was slight at best in all four vowels, with the greatest amount of fronting occurring in the front vowel /e/. The tongue tip was clearly lowered in the [+ATR] allophone of each of the three back vowels /u/, /o/, and /a/.

\section{Speaker 3}

Midsagittal and posterior coronal $\mathrm{TaO}$ images for the [+ATR] and [-ATR] allophones of the vowel /e/, /o/, and /a/ are shown in Fig. 6 (recall that the vowel /u/ was not recorded by speaker 3). For the vowel /e/, the only apparent difference is that the $[+\mathrm{ATR}]$ allophone has a raised tongue dorsum. Notice that the field of view in the midsagittal plane is considerably smaller than for speaker 5, and the image quality is noisier. We suggest that the raising of the tongue dorsum must be accompanied by advancement of the tongue root because of volume preservation, and the reason why tongue root advancement is not observed is because it is outside the field of view.

For the vowel /o/, the dorsum is raised in the [+ATR] allophone. The tongue tip is lowered, and although there is no direct evidence of tongue root advancement, the slope of the tongue root is steeper in the [+ATR] allophone, suggesting that the lack of direct evidence is due to the relevant part of the tongue root falling outside of the field of view. As with the vowel /e/, we suggest that volume preservation by means of advancing the tongue root must accompany the raised dorsum.

For the vowel /a/, the dorsum is raised in the [+ATR] allophone and the tongue tip is lowered. There is no direct evidence of tongue root advancement, although once again we suggest that volume preservation requires it.

Speaker 3 was the only speaker out of the five to present little or no direct evidence of tongue root advancement in [+ATR] vowel allophones. This speaker also had the poorest image quality overall and smallest field of view, increasing the likelihood that any tongue root advancement would be obscured and immeasurable. Nevertheless, indirect evidence, including the requirement that volume be preserved in an incompressible muscular hydrostat (Gilbert et al., 2007), points to a likely involvement of the tongue root in the production of these allophones. This explanation is supported 

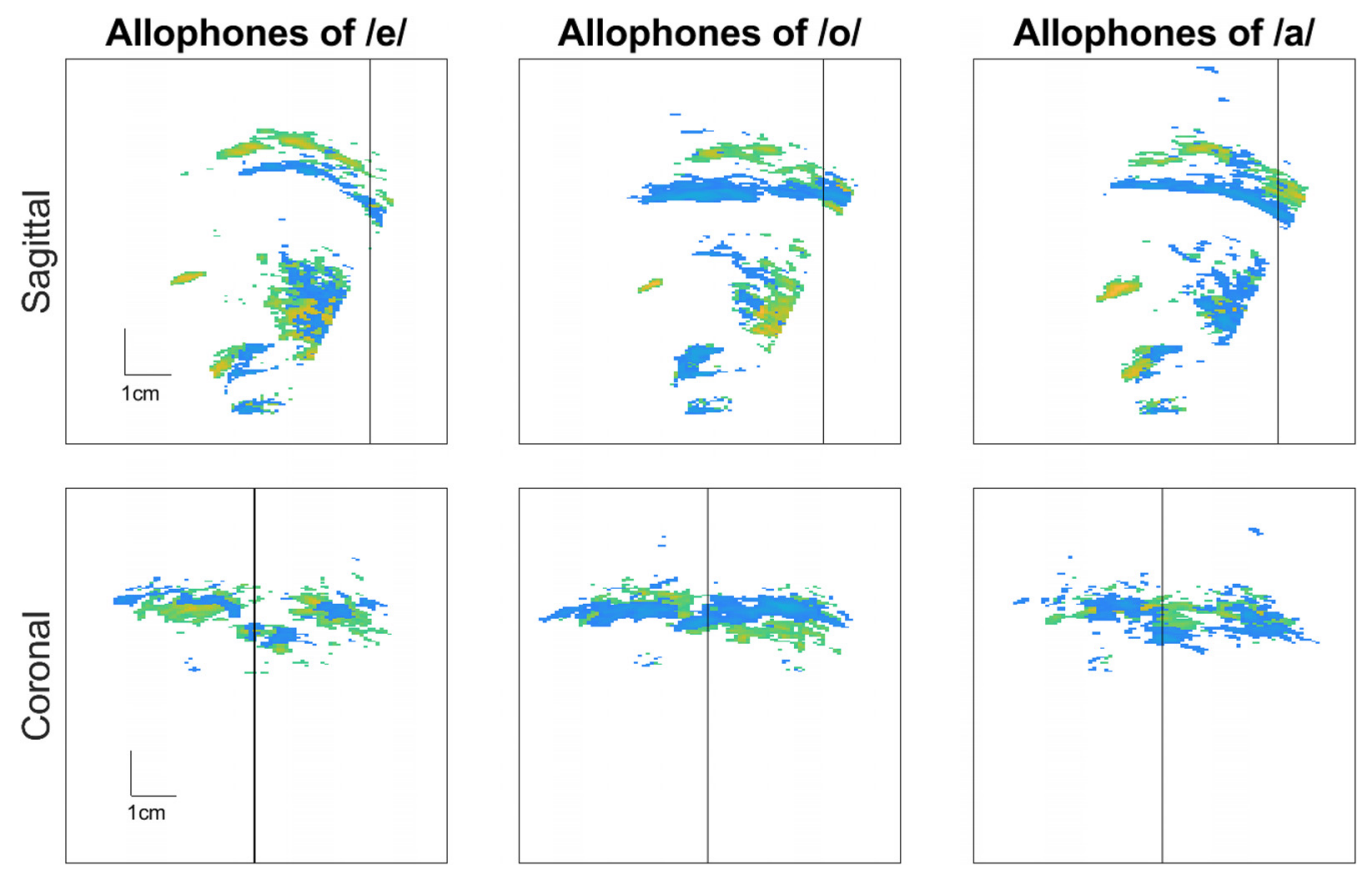

FIG. 6. Comparison of the words tetet vs ciecieć, totot vs ciocioć, and tatat vs ciaciać, produced by speaker 3 . The tongue tip is to the left in all panels of the top row. Green, prepalatal context; blue, neutral context.

by the observed uniform raising of the tongue dorsum, since the raised volume of the tongue must be balanced by advancing the tongue volume in the root region.

Unlike for speaker 5, raising of the tongue dorsum was a consistent feature of speaker 3's [+ATR] allophones, while there was little or no evidence of fronting in any of the vowels /e/, /o/, or /a/. As with speaker 5, the tongue tip was lowered in the [+ATR] allophone of each of the back vowels /o/ and $/ \mathrm{a} /$.

\section{Speakers 1, 2, and 4}

Characteristics of the [+ATR] allophones in relation to the [-ATR] allophones are summarized for speakers 1, 2, and 4, as follows:

(1) For the vowel /e/, speakers 1, 2, and 4 showed advancement of the tongue root and raising of the tongue body with little or no fronting in the [+ATR] allophone. Speaker 2 additionally showed lowering of the tongue tip. All three speakers showed a deeper midline groove in the tongue root area.

(2) For the vowel /u/, both speakers 1 and 2 showed tongue root advancement and a deeper groove in the [+ATR] allophone with little or no fronting. Speaker 2 also showed a lower tongue tip. Recall that speaker 4 did not record the two allophones of the vowel $/ \mathrm{u} /$.

(3) For the vowel /o/, speakers 1, 2, and 4 showed a deeper groove, slight tongue root advancement, and tongue body raising with little or no fronting in the [+ATR] vowel.

(4) For the vowel /a/, speakers 1, 2, and 4 showed tongue root advancement, a slightly deeper groove, and tongue body raising with variable fronting in the $[+\mathrm{ATR}]$ allophone. Speaker 1 also showed lowering of the tongue tip.

\section{E. Articulatory phonetics of soft and hard consonants}

The soft and hard affricates and fricatives were analyzed in the same way as the vowels, except advancement of the hyoid bone was not measured. Data from all five speakers are shown in Fig. 7. Across all speakers, both the tongue root advancement and the groove depth in the soft consonants were significantly greater than in the hard consonants (see Table I). The same was true on an individual basis for all five speakers.

All five speakers present evidence of greater tongue root advancement (by $0.79 \mathrm{~cm}$, on average) during the soft consonants, together with a posterior groove that is $0.68 \mathrm{~cm}$ deeper on average. The soft and hard consonants thus display the same distinctions as the vowels but with more extreme tongue root advancement and posterior grooving in the soft consonants than in the [+ATR] vowels. This greater degree of tongue root advancement is consistent with the fact that the relevant parts of the tongue root were within the field of view for speaker 3 during the consonants, whereas they were outside the field of view for the vowels.

The differences between the soft and hard consonants are illustrated in Fig. 8 for speaker 5, who was again representative of the other speakers. In both the affricates and fricatives, in both high front vowel and low back vowel contexts, the soft consonants exhibit advancement of the tongue root, a deep posterior groove, and slight fronting of the tongue body.

\section{F. Articulatory phonetics of /i/ and / $/$ /}

The two vowel phonemes /i/ and /i/ do not participate in the allophony in the way other vowels do, i.e., they do not each have two allophones for soft and neutral contexts. Instead, the vowel /i/ appears in consonantal contexts in 

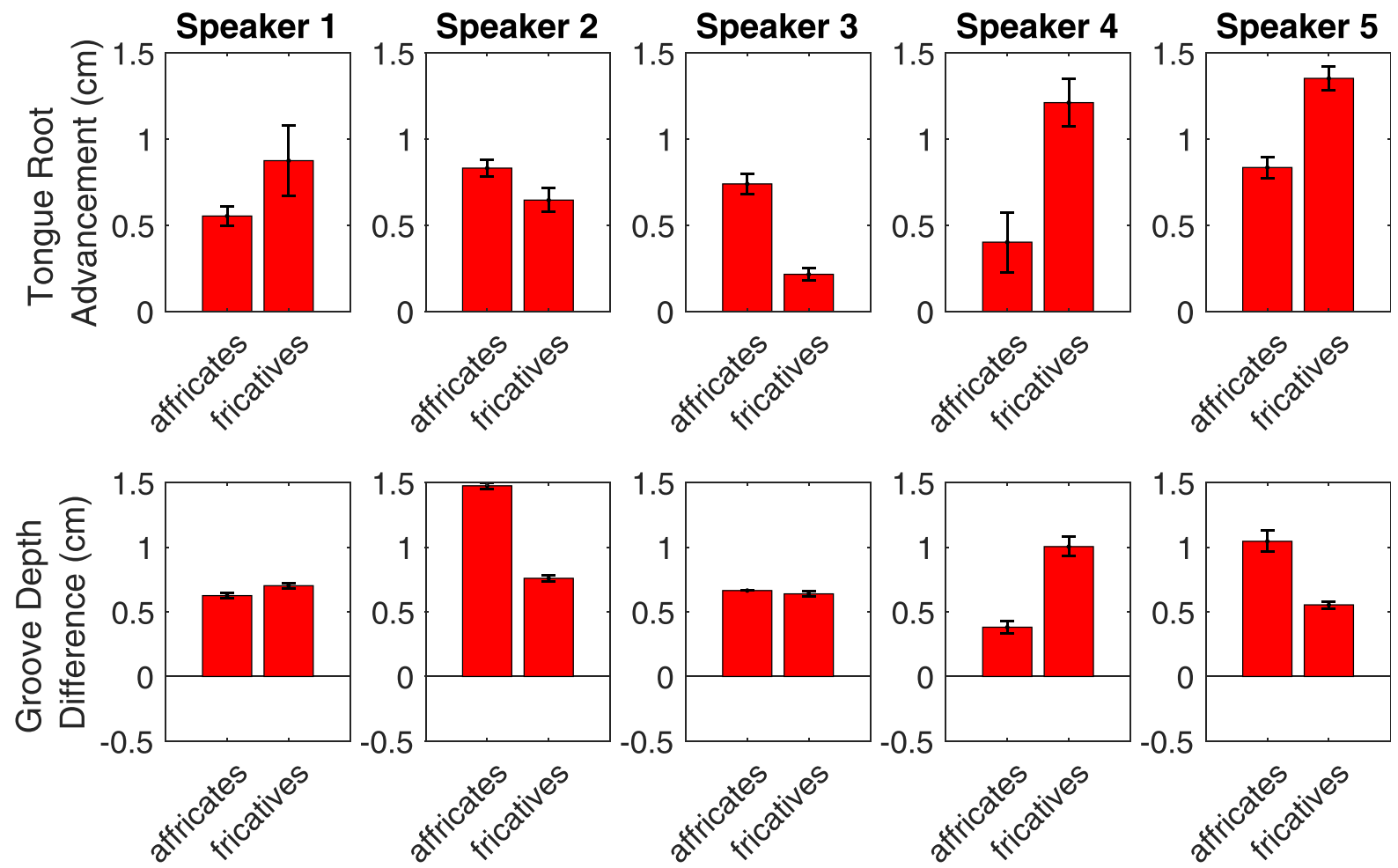

FIG. 7. (Color online) Measures of tongue root advancement, groove depth, and hyoid advancement for all five speakers in the soft vs hard consonants. Bar heights show averages, and error bars show standard deviations over three measurements.

which advanced tongue root allophones of the vowels /e, $\mathrm{u}$, $\mathrm{o}$, a/ would occur, and /i/ occurs where the non-advanced tongue root allophones would occur. This suggests that the mechanism responsible for the allophonic variation may also be responsible for the distinction between /i/ and /i/. A
Kruskal-Wallis test for a main effect of vowel was not significant (see Table I), indicating that the vowel pair /i/ - / $\mathbf{i} /$ is similar to the other soft-hard vowel pairs in Polish. Apart from the parallels in phonotactic patterning and lack of a main effect of vowel, in the following paragraphs we

\section{Affricates}
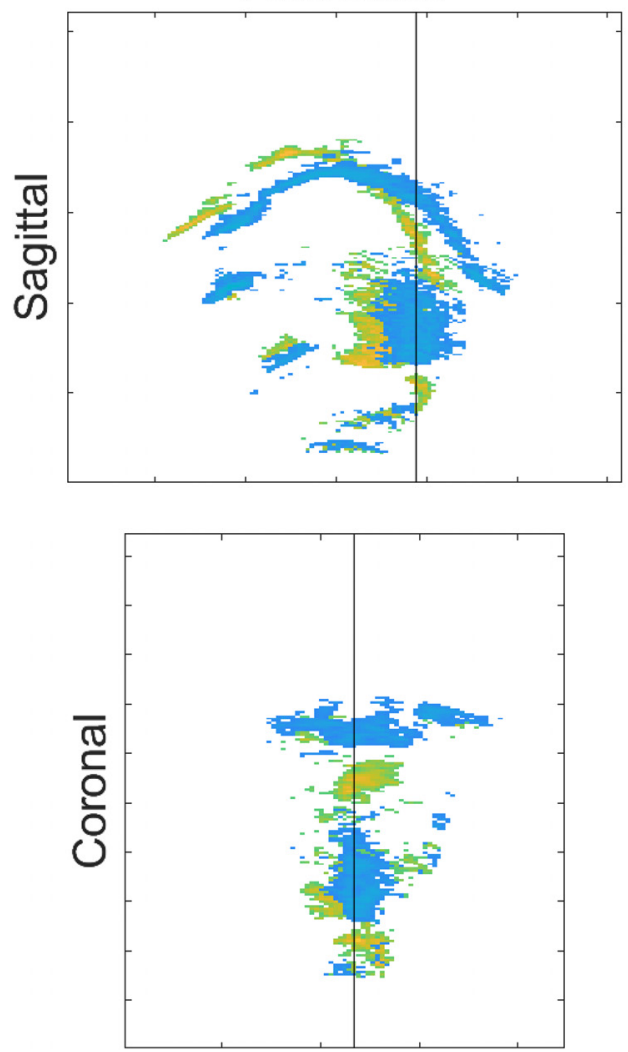

\section{Fricatives}
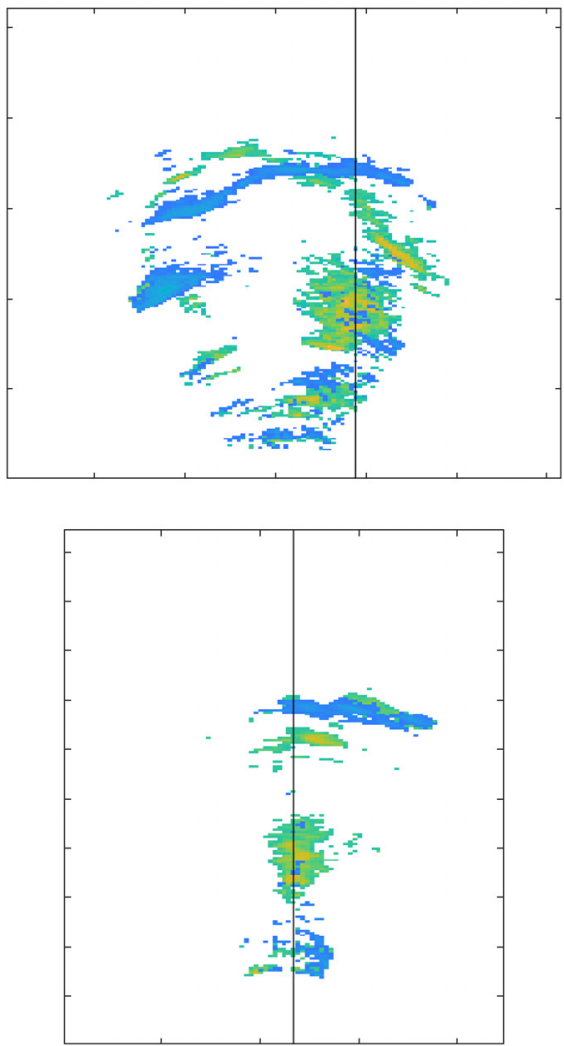

FIG. 8. TaO images comparing soft and hard affricates and fricatives produced by speaker 5 . The tongue tip is to the left in both of the top panels. Green, prepalatal context; blue, neutral context. 
demonstrate that the distinction between /i/ and / $\mathbf{i} /$ is phonetically directly comparable to the distinction between each pair of allophones for the remaining vowels.

Figure 9 presents the results of the analysis of /i/ and /i/, which parallels the analysis of the remaining vowel phonemes as presented in Sec. IV A. Since measurements from the vowels /i/ and /i/ could not be made for speaker 3 due to poor image quality, only data from speakers 1, 2, 4, and 5 are presented in Fig. 9. All four subjects produced /i/ with the tongue root further advanced by $0.60 \mathrm{~cm}$, on average, and with a posterior groove depth at least $0.66 \mathrm{~cm}$ greater than in $/ \dot{\mathbf{t}} /$. Hyoid advancement was either not visible (in speakers 2 and 4) or contrary to expectations (speakers 1 and $5)$. These findings precisely mirror those for the vowel phonemes /e, u, o, a/.

The [+ATR] vowel /i/ is produced with an advanced tongue root and deeper posterior groove, together with a raised tongue dorsum and little to no additional fronting in comparison with the $[-\mathrm{ATR}]$ vowel $/ \mathbf{i} /$. This is illustrated for each speaker in Fig. 10. As with the other vowels, speaker 3 does not directly show tongue root advancement and a deep posterior groove due to the small field of view, but the apparent added volume due to tongue dorsum raising must be compensated for elsewhere, most likely through advancement of the part of the tongue root outside the field of view.

\section{G. Acoustic phonetics}

Measured average (median) formant frequencies of each of the soft and hard vowels produced by each speaker are summarized in Table II. Pooled across speakers and vowels, the first formant was significantly lower in the soft vowels than in the hard vowels, and the second formant was significantly higher, while the third formant was not significantly different (see Table I).

\section{RESULTS-PHASE 2}

Summary statistics and vowel formants for speakers 6-10 are presented in Tables I and II, together with the data from speakers $1-5$. The magnitude of tongue root


FIG. 9. (Color online) Measures of tongue root advancement, groove depth, and hyoid advancement for all five speakers in the vowels /i, $\dot{\mathrm{t}} /$. Bar heights show averages, and error bars show standard deviations over three measurements. 

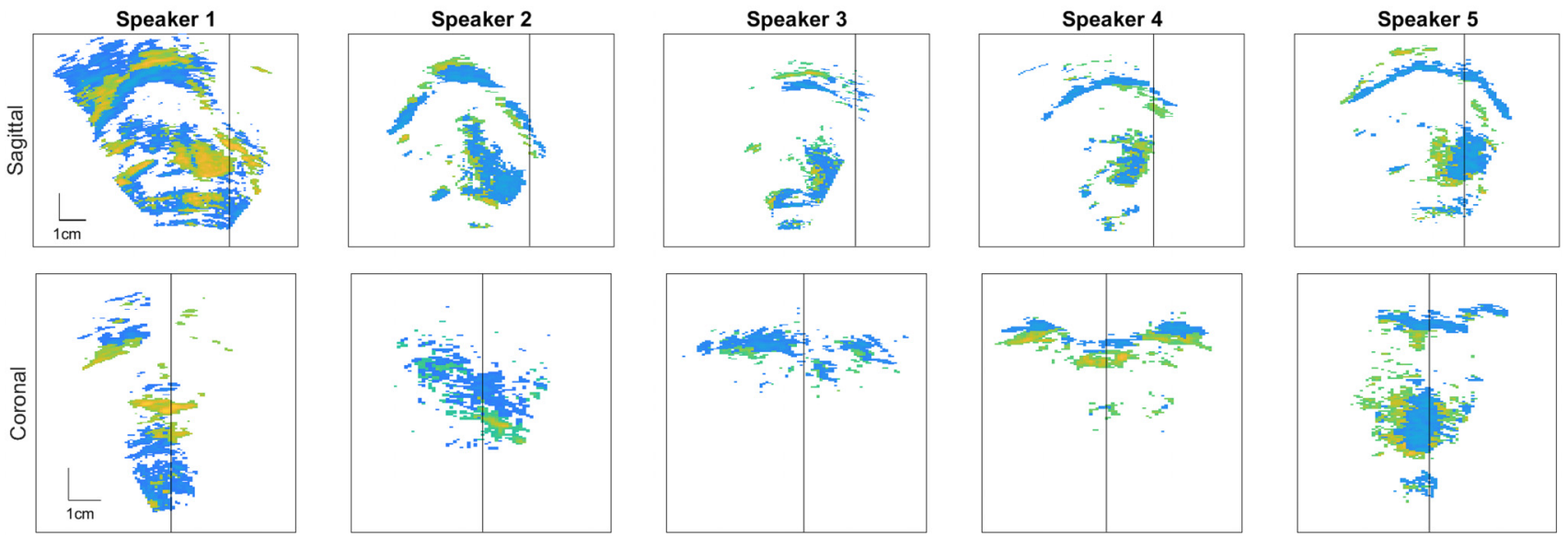

FIG. 10. Comparison of the words tytyt vs cicić, produced by all five speakers. The tongue tip is to the left in all panels of the top row. Green, prepalatal context; blue, neutral context.

advancement $(0.36 \mathrm{~cm})$ and midline groove depth $(0.21 \mathrm{~cm})$ in soft vowels and consonants was smaller than for speakers $1-5(0.45 \mathrm{~cm}$ and $0.36 \mathrm{~cm}$, respectively), but still significant. The effects of vowel softness on F1 $(-31 \mathrm{~Hz})$ and F2 $(180 \mathrm{~Hz})$ in speakers 6-10 were similar to speakers $1-5(-59 \mathrm{~Hz}$ and $171 \mathrm{~Hz}$, respectively), and significant. As with speakers 1-5, there were no main effects of speaker on any articulatory or acoustic variable. There was a marginal main effect of vowel on the difference in F3 between soft and hard vowels.

TABLE II. Measurement average formant frequencies $(\mathrm{Hz})$ for each vowel produced by each speaker. Speakers $1-5$ were from the first phase of the study, and speakers 6-10 were from the second phase. Speaker gender is given within parentheses in the first column.

\begin{tabular}{|c|c|c|c|c|c|c|c|c|c|c|c|}
\hline Speaker (m/f) & Formants & soft /i/ & $\operatorname{hard} / \mathrm{y} /$ & soft /e/ & hard /e/ & soft /a/ & hard /a/ & soft /o/ & hard /o/ & soft $/ \mathrm{u} /$ & hard /u/ \\
\hline \multirow{3}{*}{1 (f) } & $\mathrm{F} 1$ & 336 & 551 & 540 & 731 & 855 & 894 & 756 & 685 & 431 & 366 \\
\hline & $\mathrm{F} 2$ & 2713 & 2149 & 2374 & 1991 & 1698 & 1435 & 1317 & 1144 & 1395 & 1090 \\
\hline & F3 & 3259 & 3117 & 3226 & 3172 & 2977 & 2347 & 2857 & 3130 & 2829 & 3340 \\
\hline \multirow{3}{*}{$2(\mathrm{~m})$} & $\mathrm{F} 1$ & 279 & 318 & 394 & 555 & 621 & 682 & 510 & 576 & 305 & 295 \\
\hline & $\mathrm{F} 2$ & 2173 & 1871 & 1904 & 1754 & 1540 & 1391 & 1302 & 1172 & 1428 & 1272 \\
\hline & F3 & 3022 & 2669 & 2768 & 2693 & 2385 & 2763 & 2429 & 2808 & 2500 & 3093 \\
\hline \multirow{3}{*}{3 (f) } & $\mathrm{F} 1$ & 421 & 528 & 564 & 664 & 809 & 774 & 620 & 744 & - & - \\
\hline & F2 & 2307 & 1905 & 2045 & 1834 & 1380 & 1410 & 1444 & 1164 & - & - \\
\hline & F3 & 2912 & 2827 & 2696 & 2723 & 2380 & 2614 & 2330 & 2816 & - & - \\
\hline \multirow{3}{*}{4 (f) } & $\mathrm{F} 1$ & 293 & 486 & 499 & 710 & 807 & 896 & 676 & 673 & - & - \\
\hline & $\mathrm{F} 2$ & 2061 & 1952 & 2075 & 1904 & 1712 & 1593 & 1564 & 1336 & - & - \\
\hline & $\mathrm{F} 3$ & 3220 & 2912 & 2898 & 2935 & 2497 & 2910 & 2491 & 2847 & - & - \\
\hline \multirow{3}{*}{$5(\mathrm{~m})$} & $\mathrm{F} 1$ & 326 & 386 & 446 & 565 & 689 & 683 & 549 & 592 & 393 & 400 \\
\hline & $\mathrm{F} 2$ & 2313 & 1768 & 2090 & 1608 & 1450 & 1334 & 1336 & 1234 & 1554 & 1185 \\
\hline & F3 & 3106 & 2518 & 2564 & 2357 & 2306 & 2525 & 2858 & 2730 & 3055 & 2622 \\
\hline \multirow{3}{*}{6 (f) } & $\mathrm{F} 1$ & 484 & 473 & 453 & 575 & 839 & 1003 & 653 & 761 & 504 & 500 \\
\hline & F2 & 2544 & 1902 & 2136 & 1771 & 1664 & 1691 & 1355 & 1219 & 1471 & 1263 \\
\hline & F3 & 2836 & 2830 & 2646 & 3023 & 2457 & 3009 & 2372 & 3280 & 2717 & 3051 \\
\hline \multirow{3}{*}{7 (f) } & $\mathrm{F} 1$ & 352 & 443 & 523 & 746 & 808 & 897 & 717 & 747 & 432 & 455 \\
\hline & $\mathrm{F} 2$ & 2397 & 1940 & 2059 & 1771 & 1564 & 1479 & 1294 & 1184 & 1119 & 994 \\
\hline & F3 & 3152 & 2789 & 2779 & 2759 & 2573 & 2699 & 2495 & 2745 & 2594 & 2907 \\
\hline \multirow{3}{*}{$8(\mathrm{~m})$} & F1 & 467 & 469 & 464 & 547 & 757 & 845 & 537 & 564 & 510 & 505 \\
\hline & $\mathrm{F} 2$ & 2205 & 1941 & 1881 & 1706 & 1519 & 1449 & 1320 & 1187 & 1589 & 1166 \\
\hline & F3 & 2751 & 2537 & 2523 & 2488 & 2688 & 2731 & 2482 & 2674 & 2428 & 2488 \\
\hline \multirow{3}{*}{$9(\mathrm{~m})$} & $\mathrm{F} 1$ & 359 & 368 & 431 & 511 & 708 & 761 & 652 & 495 & 357 & 397 \\
\hline & $\mathrm{F} 2$ & 2031 & 1854 & 1890 & 1841 & 1399 & 1231 & 1792 & 842 & 1241 & 941 \\
\hline & F3 & 3150 & 2564 & 2681 & 2609 & 2671 & 2799 & 2658 & 2979 & 2073 & 2525 \\
\hline \multirow{3}{*}{$10(\mathrm{~m})$} & $\mathrm{F} 1$ & 363 & 404 & 473 & 531 & 655 & 686 & 609 & 604 & 448 & 472 \\
\hline & $\mathrm{F} 2$ & 2030 & 1921 & 1724 & 1538 & 1351 & 1292 & 1258 & 1051 & 1399 & 1423 \\
\hline & F3 & 3089 & 2839 & 2618 & 2677 & 2523 & 2680 & 2884 & 2831 & 2816 & 2483 \\
\hline
\end{tabular}


The differences between soft and hard vowels, and soft and hard consonants, produced by speakers 6-10 ( $\mathrm{TaO}$ images not shown) were similar to those produced by speakers 1-5. Considering all of the data together, the second phase of the study successfully replicated the findings from the first phase.

\section{DISCUSSION}

This study pursued three goals:

(1) Provide an articulatory phonetic description of Polish vowel allophony.

(2) Determine whether a phonological interpretation of the allophony in terms of [ATR] is supported phonetically.

(3) Determine whether articulatory phonetic evidence supports viewing the contrast between /i/ and /i/ as identical to the allophonic contrast among the other Polish vowels.

\section{A. Articulatory description of Polish vowel allophony}

Research from the 1990s claimed that Polish vowels in the context of soft consonants were systematically fronted and/or raised (e.g., Sawicka, 1995; Wisniewski, 1997). Specifically, /u/ was predicted to be fronted, /a/ raised, and /e, o/ both fronted and raised. The results of this study only minimally support these predictions. For each vowel, the degree of fronting or raising was variable across the five speakers:

(1) The vowel $/ \mathrm{u} /$ in soft context was marginally fronted only for speaker 5 .

(2) The vowel /a/ was raised by all five speakers but only minimally fronted.

(3) The vowel /e/ was raised without fronting by speakers $1-4$, but both raised and fronted by speaker 5 .

(4) The vowel /o/ was raised without fronting by all five speakers (although for speaker 5, even raising was minimal).

In most cases, the tongue tip was lowered during the vowel in the soft context, even when the tongue body was raised. The variability in fronting and raising, together with tongue tip lowering during the allophones in soft contexts, supports an analysis in which these differences are understood as collateral effects of the primary articulatory gesture, consistent with Cavar (2004, 2007, 2018), who posited tongue root advancement as the primary gesture.

\section{B. Tongue root advancement in Polish vowel allophony}

Through analyses of the vowels /e, u, o, a/ in soft and neutral consonant contexts, it was found that advancement of the tongue root and consequent formation of a deep posterior tongue groove were consistent characteristics of the vowel allophones in soft consonant contexts. As noted above, some adjustments to tongue body height and fronting were also observed, but these were inconsistent across the variety of vowels and speakers. Contrary to expectations, advancement of the hyoid bone was not consistently associated with either set of allophones.

The degree of tongue root advancement observed in Polish [+ATR] vowels $(0.36-0.45 \mathrm{~cm})$ is similar to that reported for Akan in Tiede (1996) and Dagbani in Hudu (2010), both of whom reported differences of about $0.5 \mathrm{~cm}$ in the tongue root position of [+ATR] vs [-ATR] vowel pairs.

The findings support an analysis of Polish vowel allophony as involving the feature [ATR], with the allophones in soft consonant contexts realized as [+ATR] and the allophones in neutral consonant contexts realized as [-ATR]. (We plan to address this distinction in a follow-up study.) Furthermore, the negative finding with respect to hyoid bone advancement suggests that tongue root advancement during speech may be a function of different muscular contractions than hyoid bone raising. For example, it could be that the GGp muscle is active in tongue root advancement without concurrent $\mathrm{GH}$ muscle activation.

The proposal that Polish vowel allophony involves the feature [ATR] is further supported by analyses of soft and hard consonants. In both affricates and fricatives, and in both high front vowel and low back vowel contexts, the differences observed between the soft and hard consonants exactly mirrored those observed in the vowels. In fact, the differences were more extreme in the consonants, which may suggest that the allophony originated diachronically from gradient coarticulation of the tongue root gesture from the consonant to the vowel. This is consistent with the widespread view that the soft consonants trigger the vowel allophony. We propose that this is synchronically represented as spreading of the feature [ATR] from the (specified) consonant to the (unspecified) vowel.

\section{Articulatory phonetics of $/ \mathrm{i} /$ and $/ \mathrm{i} /$}

Although the vowels /i/ and /i/ are phonemically distinct (i.e., they are not allophones of a single vowel) and do not participate in allophony like the remaining vowels, the analyses presented in this study show that their articulatory differences are exactly parallel to the differences observed for the other vowels and soft and hard consonants. Specifically, tongue root advancement and posterior groove deepening was observed in the vowel/i/ for all five speakers (confirming an observation in Wierzchowska, 1967). Furthermore, the tongue body was raised but not fronted in /i/, suggesting the vowel $/ \mathbf{i} /$ is a front vowel, rather than a central or back vowel (contrary to, e.g., Gussmann, 1992; Nowak, 2000; Rubach, 1984; Szpyra, 1995).

\section{Acoustic phonetics of Polish vowel allophony}

Formant measurements confirmed global differences in both F1 and F2 for the [+ATR] vs [-ATR] vowel allophones. Specifically, F1 was lower and F2 was higher in [+ATR] allophones. Acoustic phonetic studies of other languages with established [ATR] vowel harmony processes have yielded similar results. One of the most closely matched examples is Western Buriat, for which the [+ATR] vowels have lower F1 and higher F2 than the [-ATR] vowels (Kang and Ko, 2012). Other languages with [ATR] vowel 
contrasts exhibit consistently lower F1 in [+ATR] vowels, but inconsistent differences in F2 [e.g., Tsongol Buriat and Ewen (Kang and Ko, 2012); Kalenjin (Local and Lodge, 2004); Maa (Guion et al., 2004); Degema (Fulop et al., 1998); Baarin, Siliingol, Khalkha, and Solon (Svantesson, 1985); Akan (Tiede, 1996), Oroqen (Lulich and Whaley, 2012)]. Ladefoged and Maddison (1996) claimed that [+ATR] vowels almost always have higher F2 than corresponding [-ATR] vowels. This characterization exactly matches the data for Polish, although its claimed nearuniversality was criticized by Beltzung et al. (2018).

\section{E. Phonology of Polish vowels, palatalization, and [ATR]}

One consequence of the study's findings is that the Polish vowel inventory can be interpreted as a symmetric system with the same phonologically active distinctions across the whole set of vowels. Specifically, it was found that the articulatory distinction between the phonemes /i/ and $/ \mathbf{i} /$ is the same as the distinction between the soft and hard allophones of the remaining vowels. In contrast, prior analyses of /it/ as a back unrounded vowel yield an asymmetric inventory with a number of conspicuous gaps, such as the absence of a hard front vowel, and unrounded counterparts to the other back vowels.

Beyond showing that the $/ \mathrm{i} /-\mathrm{l} / \mathrm{i}$ contrast mirrors the softhard contrast in the other vowels, the findings also demonstrated that the same articulatory distinctions are present among the soft and hard consonants of Polish. We therefore propose a phonological analysis in which the vowel phonemes and soft and hard consonant phonemes have distinctive feature specifications as follows. The vowel /i/ and consonants $/ \mathrm{t}_{\mathrm{c}} /$ and $/ \mathrm{c}_{\phi} /$ (and their voiced counterparts) are all [+ATR], the consonants /s/ and /tšs/ (and their voiced counterparts) are $[-\mathrm{ATR}]$, and the remaining vowels /e, a, o, u/ and neutral consonants (e.g., /t, k/) are unspecified for the feature [ATR]. We propose that in Polish a consonant-vowel sequence must exhibit "agreement" in terms of the [ATR] specification. A vowel that is unspecified for [ATR] therefore becomes [+ATR] following a soft consonant, [-ATR] following a hard consonant, and remains unspecified for [ATR] following a neutral consonant. On the other hand, the [+ATR] vowel /i/ can only occur following a soft [+ATR] or neutral consonant, while the [-ATR] vowel / $\mathbf{t} /$ can only occur following a hard [-ATR] or neutral consonant. A neutral consonant followed by /i/ is palatalized or "softened" by the vowel and becomes [+ATR], while a neutral consonant followed by /i/ becomes [-ATR].

This study provides evidence that the feature [ATR] is active not only in vowels but also in consonants, and raises the possibility that consonants (like /q/) co-occuring with [-ATR] vowels are specified [-ATR], while consonants (like /k/ ) co-occuring with [+ATR] vowels are specified [+ATR] as in Tungusic languages (Ard, 1983). We also speculate that the feature [ATR] might drive all phonetic palatalization processes, or at least that it is involved in palatalization processes, as observed by Bennett et al. (2018) for Connemara Irish.

\section{F. Limitations}

Although the first phase of the study was successfully replicated in the second phase, the total number of ten speakers of a relatively uniform dialect begs the question how the results might generalize to speakers of other dialects and languages. Moreover, although we speculate that the findings from this study shed light on palatalization and the role of the feature $[\mathrm{ATR}]$ in consonants, these speculations are substantiated in this study only for standard Polish. We therefore plan to carry out a parallel study of Russian vowels and consonants, and to expand our investigation to include other consonant-vowel interactions that seem to involve the tongue root such as emphasis in Arabic.

Although the spatial resolution of the ultrasound images used in this study was excellent, the temporal resolution was merely acceptable (especially for the first phase of the study). In the future it would be worthwhile to increase the temporal resolution, perhaps by sacrificing visibility of parts of the sides of the tongue, or focusing specifically on the tongue root while sacrificing visibility of the tongue blade. Although we did not find any relationship between tongue root advancement and hyoid elevation/advancement, this could be due to the fact that we were simply unable to identify the anterior end of the acoustic shadow cast by the hyoid bone in many cases.

As we indicated in Sec. III A, this study does not provide evidence of specific muscle contractions leading to changes in tongue shape and position, especially the formation of the midline groove and advancement of the tongue root. Instead, this study measured changes in the position of the tongue surface at locations that were defined by tongue anatomy, which is generally easily visible within ultrasound images (e.g., the tendon of the GGp). The resulting observations of consistent tongue root advancement and midline grooving in soft vowels and consonants may suggest contraction of the posterior GGp muscle, perhaps in combination with other tongue muscle contractions, but they do not depend on such an interpretation. More work is needed to determine the muscle activation patterns underlying these observations, using methods other than those employed in this study.

\section{CONCLUSIONS}

This study explored the articulatory phonetic implications of Cavar's proposal that Polish vowel allophony (at least for the front vowels) was governed by the feature [ATR] (Cavar, 2004, 2007, 2018). An anatomical/physiological definition for the parts of the tongue surface commonly referred to as the root, dorsum, blade, and tip was proposed, and potential muscular mechanisms for tongue root advancement were deduced. Physiological considerations, including the fact that the tongue is a muscular hydrostat, together with Cavar's proposal on phonological grounds, supported the predictions that (1) the tongue root would be more advanced in the soft vowel allophones than in the neutral allophones, (2) the tongue root would have a deeper midline groove in the soft allophones than in the neutral allophones, and (3) the hyoid bone would be advanced in the soft 
allophones relative to the neutral allophones. The first and second of these predictions were consistently supported by the analyses. The third prediction (regarding hyoid advancement) was not supported. The first two predictions were also found to be true for the contrasting vowels /i/ and / $\mathbf{i} /$ and the contrasting soft and hard posterior affricates and fricatives. Across all vowels, tongue raising and fronting were not consistent markers of the soft vowel allophones, contrary to some previous studies. An acoustic phonetic analysis confirmed the vowels of Polish patterns like those in known [ATR] vowel systems.

On the basis of the articulatory evidence gleaned from 3D/4D ultrasound recordings of Polish vowels and consonants, we conclude that the Polish vowel allophony is indeed governed by the feature [ATR], the vowels /i/ and / $\mathbf{i} /$ are distinguished by the same feature, and the consonantal triggers of the allophony (soft) are also distinguished by the same feature from the hard consonants. Specifically, we conclude that the Polish sounds /i, t $6, \mathrm{~d} z, 6, z_{/} /$are phonologically specified as [+ATR], and the sounds /ít, ťs, dž, s, z/ are phonologically specified as $[-\mathrm{ATR}]$. We propose that the remaining vowels /e, a, o, u/ are unspecified for [ATR] in their underlying representations and only receive such a specification from a neighboring soft or hard consonant. Finally, we conclude that neutral consonants are unspecified for [ATR] in their underlying representations and only receive such a specification from the neighboring vowels $/ i$, $\dot{\mathbf{i}} /$, which are specified for [ATR] in their underlying representations.

In addition to offering a fully symmetric vowel system for Polish and an explanation of the interactions between vowels and consonants in Polish, these results may have implications for understanding soft and hard consonants, vowel allophony, and palatalization processes in other languages. In particular, these results raise the strong possibility that palatalization processes, in general, may involve tongue root advancement, perhaps even in place of widely held theories that attribute palatalization to coronal or dorsal tongue features.

\section{ACKNOWLEDGMENTS}

We would like to thank Max Nelson and Olivia Foley for their help with data collection for this project. We also thank the two anonymous reviewers and the Associate Editor for their helpful comments and feedback.

${ }^{1}$ Ultrasound and audio recordings from all 10 subjects are available upon request from the corresponding author. The dataset is planned to be archived through the Indiana University IUScholarWorks program.

${ }^{2}$ The toolbox is available for free download at http://www.indiana.edu/ $\sim$ spliu/WASL.htm (Last viewed 9/23/2019).

Aralova, N., Grawunder, S., and Winter, B. (2008). "The acoustic correlates of tongue root vowel harmony in even (Tungusic)," in Proceedings of the 17th International Congress of Phonetic Sciences (ICPhS XVII), pp. 240-243.

Archangeli, D., and Pulleyblank, D. (1994). Grounded Phonology (MIT Press, Cambridge, MA).

Ard, J. (1983). "A sketch of vowel harmony in the Tungus languages," Res. Lang. Social Interact. 16, 23-43.
Beltzung, J.-M., Patin, C., and Clements, G. N. (2018). "The feature [ATR]," in Features in Phonology and Phonetics, edited by A. Rialland, R. Ridouane, and H. van der Hulst (De Gruyter, Berlin), pp. 217-246.

Bennett, R., Ní Chiosáin, M., Padgett, J., and McGuire, G. (2018). "An ultrasound study of Connemara Irish palatalization and velarization," J. Int. Phonetic Assoc. 48(3), 261-304.

Boersma, P., and Weenink, D. (2018). "Praat: Doing phonetics by computer (version 6.1.03) [computer program]," http://www.praat.org (Last viewed 9/23/2019).

Catford, J. C. (1988). A Practical Introduction to Phonetics (Clarendon, Oxford).

Cavar, M. E. (2004). "Palatalization in Polish: An interaction of articulatory and perceptual factors," Ph.D. thesis, University of Potsdam.

Cavar, M. E. (2007). “[ATR] in Polish,” J. Slavic Linguist. 15(2), 207-228.

Cavar, M. E. (2018). "The elusive Polish [i: Partial results of an ultrasound imaging study]," in Phonology, Fieldwork and Generalizations, edited by B. Czaplicki, B. Lukaszewicz, and M. Opalinska (Lang, Berlin), pp. 215-238.

Charles, S., and Lulich, S. M. (2018). "Case study of Brazilian Portuguese laterals using a novel articulatory-acoustic methodology with 3D/4D ultrasound," Speech Commun. 103, 37-48.

Charles, S., and Lulich, S. M. (2019). "Articulatory-acoustic relations in the production of alveolar and palatal lateral sounds in Brazilian Portuguese," J. Acoust. Soc. Am. 145, 3269-3288.

Dejna, K. (1983). Dialekty polskie (Polish Dialects) (Ossolineum, Wrocław).

Dejna, K. (1994). Atlas polskich innowacji dialektalnych (Atlas of Polish Dialectal Innovations) (Panstwowe Wydawnictwo Naukowe, WarszawaŁódź).

Fulop, S. A., Kari, E., and Ladefoged, P. (1998). "An acoustic study of the tongue root contrast in Degema vowels," Phonetica 55, 80-98.

Gilbert, R. J., Napadow, V. J., Gaige, T. A., and Wedeen, V. J. (2007). "Anatomical basis of lingual hydrostatic deformation," J. Exp. Biol. 210, 4069-4082.

Greenberg, M. L., Borowski, K. E., Schallert, J., and Woolhiser, C. F. (2017). "Slavic dialectology: A survey of research since 1989," J. Slavic Linguist. 25, 303-336.

Guion, S., Post, M. W., and Payne, D. L. (2004). "Phonetic correlates of tongue root vowel contrasts in Maa," J. Phonetics 32, 517-542.

Gussmann, E. (1992). "Back to front: Non-linear palatalization in Polish," in Phonological Investigations, edited by J. Fisiak and S. Puppel (Benjamins, Amsterdam), pp. 5-66.

Halle, M., and Stevens, K. N. (1969). "On the feature 'advanced tongue root,”" MIT Res. Lab. Electron. Q. Prog. Rep. 94, 209-215.

Hansson, G. (2001). "Theoretical and typological issues in consonant harmony," Ph.D. thesis, University of California, Berkeley.

Hess, S. (1988). "Acoustic characteristics of the vowel harmony feature and vowel raising in Akan," in UCLA Working Papers in Phonetics (UCLA, Los Angeles, CA), pp. 58-72.

Hiiemae, K. M., Palmer, J. B., Medicis, S. W., Hegener, J., Jackson, B. S., and Lieberman, D. E. (2002). "Hyoid and tongue surface movements in speaking and eating," Arch. Oral Biol. 47, 11-27.

Hill, J. H., and Zepeda, O. (1992). "Derived words in tohono o'odham," Int. J. Am. Ling. 58, 355-404.

Honda, K. (2008). "Physiological processes of speech production," in Springer Handbook of Speech Processing, edited by J. Benesty, M. M. Sondhi, and Y. A. Huang (Springer, Berlin), pp. 7-26.

Hudu, F. A. (2010). "Dagbani tongue-root harmony:A formal account with ultrasound investigation," Ph.D. thesis, University of British Columbia, Vancouver, Canada.

Kang, H., and Ko, S. (2012). "In search of the acoustic correlates of tongue root contrast in three altaic languages: Westurn Buriat, Tsongol Buriat, and Ewen," J. Altaic Soc Korea 22, 179-203.

Keyser, S. J., and Stevens, K. N. (2006). "Enhancement and overlap in the speech chain," Language 82, 33-63.

Koneczna, H., and Zawadowski, W. (1951). Przekroje rentgenograficzne glosek polskich (X-ray Cross-Sections of Polish Sounds) (Panstwowe Wydawnictwo Naukowe, Warszawa-Łódź).

Ladefoged, P., De Clerk, J., Lindau, M., and Papgun, G. (1972). "An auditory-motor theory of speech production," in UCLA Working Papers in Phonetics (UCLA, Los Angeles, CA), pp. 48-75.

Ladefoged, P., and Maddison, I. (1996). The Sounds of the World's Languages (Blackwell, Boston). 
Lindau, M. (1975). "Features for vowels," in UCLA Working Papers in Phonetics (UCLA, Los Angeles, CA), pp. 16-21.

Lindau, M. (1978). “The feature expanded,” J. Phonetics 7, 163-177.

Local, J., and Lodge, K. (2004). "Some auditory and acoustic observations on the phonetics of [ATR] harmony in a speaker of a dialect of Kalenjin," J. Int. Phonetic Assoc. 34, 1-16.

Lulich, S. M., Berkson, K. H., and de Jong, K. (2018). "Acquiring and visualizing 3D/4D ultrasound recordings of tongue motion," J. Phonetics 71, $410-424$.

Lulich, S. M., and Whaley, L. J. (2012). "An acoustic phonetic study of Oroqen vowels," in Recent Advances in Tungusic Linguistics, edited by A. L. Malchukov and L. J. Whaley (Harrassowitz, Wiesbaden, Germany), pp. 61-80.

Niimi, S., and Simada, Z. (1980). "Ultrasonic investigation of tongue shape,” Jpn. J. Logoped. Phoniatr. 21, 121-125.

Nowak, P. (2000). "Palatalization in Polish: An optimality-theoretic approach," Master's thesis, Harvard University.

Pike, K. (1947). Phonemics (University of Michigan Press, Ann Arbor, MI).

Pulleyblank, D. (2015). "Vowel height," in The Blackwell Companion to Phonology, edited by M. van Ostendoorp, C. Ewen, E. V. Hume, and K. Rice (Wiley-Blackwell, Boston), pp. 491-518.

Rose, S. (1996). "Variable laryngeals and vowel lowering," Phonology 13, 73-117.

Rubach, J. (1984). Cyclic and Lexical Phonology: The Structure of Polish (de Gruyter, Berlin).

Saugusa, H., Niimi, S., Yamashita, K., Gotoh, T., and Kumada, M. (2001). "Morphological and histochemical studies of the genioglossus muscle," Ann. Otol., Rhinol., Laryngol. 110, 779-784.

Sawicka, I. (1995). "Fonologia" ("Phonology)," in Fonetyka i fonologia (Phonetics and Phonology), edited by H. Wrobel (Wydawnictwo Instytutu Jezyka Polskiego PAN, Katowice, Poland), pp. 105-195.
Scobbie, J. M., Wrench, A. A., and van der Linden, M. (2008). "Head-probe stabilisation in ultrasound tongue imaging using a headset to permit natural head movement," in Proceedings of the 8th International Seminar on Speech Production, pp. 373-376.

Stewart, J. M. (1967). "Tongue root position in Akan vowel harmony," Phonetica 16, 185-204.

Stone, M. (2005). "A guide to analyzing tongue motion from ultrasound images," Clin. Linguist. Phonetics 19, 455-501.

Stone, M., and Lundberg, A. J. (1996). "Three-dimensional tongue surface shapes of English consonants and vowels," J. Acoust. Soc. Am. 99, 3728-3737.

Svantesson, J.-O. (1985). "Vowel harmony shift in Mongolian," Lingua 67, $283-327$.

Szpyra, J. (1995). Three Tiers in Polish and English Phonology (Wydawnictwo Uniwersytetu Marii Curie-Skłodowskiej, Lublin, Poland).

Tiede, M. (1996). "An MRI-based study of pharyngeal volume contrasts in Akan and English," J. Phonetics 24, 399-421.

Trigo, L. (1986). "Voicing and pharyngeal expansion: ATR harmony in Buchan and Madurese" (unpublished).

Trigo, L. (1991). "On pharynx-larynx interactions," Phonology 8, 113-136.

Vaux, B. (1992). “The status of ATR in feature geometry," Linguist. Inquiry 27, 175-182.

Washington, J. N. (2016). "An investigation of vowel anteriority in three Turkic languages using ultrasound tongue imaging," Ph.D. thesis, Indiana University, Bloomington, IN.

Wierzchowska, B. (1967). Opis fonetyczny jezyka polskiego (Phonetic Description of the Polish Language) (Panstwowe Wydawnictwo Naukowe, Warszawa-Łódź).

Wisniewski, M. (1997). Zarys fonetyki i fonologii wspolczesnego jezyka polskiego (Outline of Phonetics and Phonology of Contemporary Polish Language) (Wydawnictwo Uniwersytetu Mikolaja Kopernika, Torun, Poland). 